\title{
Mechanical response of multi-layer bacterial cellulose nanopaper reinforced polylactide laminated composites
}

DOI:

10.1016/j.compositesa.2017.12.025

\section{Document Version}

Accepted author manuscript

Link to publication record in Manchester Research Explorer

\section{Citation for published version (APA):}

Hervy, M., Blaker, J. J., Braz, A. L., \& Lee, K. Y. (2018). Mechanical response of multi-layer bacterial cellulose nanopaper reinforced polylactide laminated composites. Composites Part A: Applied Science and Manufacturing, 107, 155-163. https://doi.org/10.1016/j.compositesa.2017.12.025

\section{Published in:}

Composites Part A: Applied Science and Manufacturing

\section{Citing this paper}

Please note that where the full-text provided on Manchester Research Explorer is the Author Accepted Manuscript or Proof version this may differ from the final Published version. If citing, it is advised that you check and use the publisher's definitive version.

\section{General rights}

Copyright and moral rights for the publications made accessible in the Research Explorer are retained by the authors and/or other copyright owners and it is a condition of accessing publications that users recognise and abide by the legal requirements associated with these rights.

\section{Takedown policy}

If you believe that this document breaches copyright please refer to the University of Manchester's Takedown Procedures [http://man.ac.uk/04Y6Bo] or contact uml.scholarlycommunications@manchester.ac.uk providing relevant details, so we can investigate your claim.

\section{OPEN ACCESS}


Mechanical response of multi-layer bacterial cellulose nanopaper reinforced polylactide laminated composites

Martin Hervy ${ }^{1}$, Jonny J Blaker ${ }^{2}$, Ana Letícia Braz ${ }^{2}$ and Koon-Yang Lee ${ }^{1 *}$

${ }^{1}$ The Composites Centre, Department of Aeronautics, Imperial College London, South Kensington Campus, SW7 2AZ, London, United Kingdom

${ }^{2}$ Bio-Active Materials Group, School of Materials, MSS Tower, The University of Manchester, Manchester, M13 9PL, United Kingdom

*Corresponding author. E-mail: koonyang.lee@imperial.ac.uk; Tel: +44 (0)20 75945150

\begin{abstract}
In this study, we investigated the mechanical response of polylactide (PLLA) reinforced with multiple layers of BC nanopaper. Laminated composites consisting of 1, 3, 6 and 12 sheet(s) of $\mathrm{BC}$ nanopaper were produced. It was observed that increasing the number of $\mathrm{BC}$ nanopaper led to an increase in the porosity of the resulting BC nanopaper-reinforced PLLA laminated composites. The tensile moduli of the laminated composites were found to be $\sim 12.5$ - 13.5 GPa, insensitive to the number of sheets of $\mathrm{BC}$ nanopaper in the composites. However, the tensile strength of the laminated composites decreased by up to $25 \%$ (from 121 $\mathrm{MPa}$ to $95 \mathrm{MPa}$ ) when the number of reinforcing BC nanopaper sheets increased from 1 to 12 sheets. This was attributed to the presence and severity of the scale-induced defects increased with increasing BC nanopaper sheets in the PLLA laminated composites.
\end{abstract}

\title{
Keywords
}

A. Cellulose, A. Laminates, A. Nanocomposites, B. Defects

\subsection{Introduction}

$\mathrm{BC}$ is a lightweight material produced by the fermentation of low molecular weight sugars using cellulose-producing Acetobacter [1], later renamed as Komagataeibacter. It is an ultrapure form of cellulose nanofibres approximately $50 \mathrm{~nm}$ in diameter and several 
micrometres in length [2] without impurities such as hemicellulose or lignin that are often present in wood-derived cellulose nanofibres [3]. BC is secreted directly as nanofibres by cellulose-producing bacteria, which makes up the pellicle (e.g. a thick biofilm) floating on top of a static fermentation medium. Crystallographically, BC possesses cellulose I structure [4] and X-ray diffraction showed that $\mathrm{BC}$ is highly crystalline, with a degree of crystallinity of up to $97 \%$ [5]. In terms of the mechanical properties, the elastic tensile modulus of a single $\mathrm{BC}$ nanofibre was measured to be $78 \mathrm{GPa}$ using a nanoscale three-point bending set-up conducted in an atomic force microscope [6]. Hsieh et al. [7] further estimated the tensile modulus of a single $\mathrm{BC}$ nanofibre to be $114 \mathrm{GPa}$ using Raman spectroscopy. The high tensile stiffness of BC coupled with its low density $\left(\sim 1.5 \mathrm{~g} \mathrm{~cm}^{-3}\right)$ enabled $\mathrm{BC}$ to be explored in a variety of composite applications, such as nano-reinforcement for fine structures including polymer foams [8,9], natural fibres [10,11] and polymer matrices for nanocomposite applications $[12,13]$.

To produce BC-reinforced polymer composites with mechanical performance exceeding that of neat polylactide, a BC loading fraction of greater than 30 vol.- $\%$ should be achieved within the composites [14]. In this context, the inherent network in the form of BC pellicle can be used directly as the reinforcement for polymers. Gindl and Keckes [15] solvent-exchanged $\mathrm{BC}$ pellicle from water through ethanol into acetone, followed by impregnation with a polymer solution containing dissolved cellulose acetate butyrate (CAB) in acetone. The solvent (acetone) was then evaporated to produce BC-reinforced CAB composites. At a BC loading of 32 vol.- $\%$, the tensile modulus and strength of the resulting $\mathrm{BC}$ pellicle-reinforced $\mathrm{CAB}$ were measured to be $5.8 \mathrm{GPa}$ and $128.9 \mathrm{MPa}$, respectively; a five-fold increase compared to the tensile modulus and strength of neat $\mathrm{CAB}$, which was found to be 1.2 GPa and 25.9 MPa, respectively. Yano et al. [16] fabricated BC pelliclereinforced epoxy composites by impregnating dried and consolidated BC pellicle with a UV- 
curable liquid epoxy resin. After curing, the resulting BC pellicle-reinforced epoxy composites possessed a tensile modulus and strength of $21 \mathrm{GPa}$ and $325 \mathrm{MPa}$, respectively, at a BC loading fraction of 65 wt.- $\%$.

In addition to the $\mathrm{BC}$ pellicle, the network in the form of $\mathrm{BC}$ nanopaper is also an important material form for the production of high performance BC-reinforced polymer composites. BC nanopapers are typically produced by first creating a homogeneous BC-inwater suspension, followed by dewatering using evaporation, vacuum- or gravity-driven filtration. The resulting wet $\mathrm{BC}$ filter cake is then dried using heat or combined heat and pressure to consolidate the filter cake into $\mathrm{BC}$ nanopaper. Montrikittiphant et al. [17] produced BC nanopaper-reinforced polylactide composites by laminating two thin polylactide films onto a sheet of $\mathrm{BC}$ nanopaper. The resulting composites were found to possess a tensile modulus and strength of $6.9 \mathrm{GPa}$ and $125 \mathrm{MPa}$, respectively, at a $\mathrm{BC}$ loading fraction of 65 vol.- $\%$. BC nanopaper-reinforced polyurethane composites have also been produced by impregnating a dried and well-consolidated $\mathrm{BC}$ nanopaper in polyurethane resin, followed by UV crosslinking [18]. At BC loading of 51 vol.- $\%$, the measured tensile modulus and strength of the composites were $11.6 \mathrm{GPa}$ and $151 \mathrm{MPa}$, respectively.

While it is evident that high performance polymer composites can be produced when $\mathrm{BC}$ networks (either in the form of pellicle or nanopaper) are used as the reinforcement, the mechanical properties of $\mathrm{BC}$ pellicle- or $\mathrm{BC}$ nanopaper-reinforced polymer composites reported in the literature are still based on only on a single sheet of $\mathrm{BC}$ network embedded within a polymer matrix. To the best of our knowledge, very limited studies have utilised more than one sheet of $\mathrm{BC}$ network as reinforcement for polymers. Lee et al. [19] have previously reported the mechanical properties of $\mathrm{BC}$ nanopaper-reinforced epoxy laminated composites consisting of 11 sheets of $\mathrm{BC}$ nanopaper but the focus of that study was to compare the reinforcing effect of $\mathrm{BC}$ with wood-derived cellulose nanofibres. The influence 
of the number of reinforcing $\mathrm{BC}$ networks on the mechanical response of the resulting $\mathrm{BC}$ composites is still not well understood. Furthermore, manufacturing of a composite is a scaledependent process [20]. We hypothesise that increasing the number of reinforcing $\mathrm{BC}$ networks in BC-reinforced polymer composites might present new challenges to the composite processing and properties. Therefore in this work, laminated composites consisting of $1,3,6,12$ sheet(s) of reinforcing $\mathrm{BC}$ network in the form of $\mathrm{BC}$ nanopapers are studied to identify limitations in our understanding of the mechanical response of BC composites.

\subsection{Materials and methods}

\subsection{Materials}

Poly(L-lactic acid) $($ PLLA) $($ L9000, D-content $\approx 1.5 \%$ ) was purchased from Biomer GmbH and used as the matrix for the production of $\mathrm{BC}$ nanopaper-reinforced PLLA laminated composites. 1,4-Dioxane (ACS Reagent, purity $\geq 99 \%$ ) was purchased from Sigma-Aldrich (Gillingham, UK) and used as the solvent for PLLA. Sodium hydroxide (pellets, purity $\geq$ 98.5\%) was purchased from VWR International (Lutterworth, UK). BC was extracted from commercially available nata de coco (Coconut gel in syrup, Xiangsun Ltd, Lugang Township, Changhua Country, Taiwan).

\subsection{Extraction and purification of $\mathrm{BC}$ from nata de coco}

The purification protocol of nata de coco to extract $\mathrm{BC}$ for use in composites application has been reported in our previous work [21]. Briefly, $150 \mathrm{~g}$ of nata de coco cubes were stirred in 3.5 $\mathrm{L}$ of de-ionised water at $80{ }^{\circ} \mathrm{C}$ using a magnetic stirrer. To this nata de coco suspension, $14 \mathrm{~g}$ of $\mathrm{NaOH}$ pellets were added to form a $0.1 \mathrm{M} \mathrm{NaOH}$ solution and the suspension was left to stir at $80{ }^{\circ} \mathrm{C}$ for $2 \mathrm{~h}$. The nata de coco suspension was then poured onto a metal sieve $($ mesh size $=300 \mu \mathrm{m})$ to recover the purified nata de coco cubes and the recovered cubes were rinsed with $5 \mathrm{~L}$ of de-ionised water to remove excess $\mathrm{NaOH}$ solution on the surface of the cubes. After the rinsing step, the purified nata de coco cubes were blended in $5 \mathrm{~L}$ of de- 
ionised water using a blender (Breville BVL065) operating at a maximum power output of $800 \mathrm{~W}$ for 2 min to create a BC-in-water dispersion. This BC-in-water dispersion was then centrifuged (SIGMA 4-16s, SIGMA Laborzentrifugen, Osterode am Harz, GmbH) at $6800 \times$ $g$ for $7 \mathrm{~min}$ and the supernatant was decanted. The blending-centrifugation step was repeated until a neutral $\mathrm{pH}$ was attained for the $\mathrm{BC}$-in-water dispersion. Once a neutral $\mathrm{pH}$ was attained, a final centrifugation step was performed to adjust the consistency of the BC-inwater dispersion to $2 \mathrm{wt} .-\%$ and stored at $5{ }^{\circ} \mathrm{C}$ prior to use.

\subsection{Manufacturing of BC nanopapers}

$\mathrm{BC}$ nanopapers with grammage of $50 \mathrm{~g} \mathrm{~m}^{-2}$ were prepared in this work. The previously purified BC was dispersed in water using a blender (Breville BVL065) to produce a BC-inwater dispersion of $0.1 \mathrm{wt} .-\%$ consistency. The dispersion was then vacuum filtered onto a $125 \mathrm{~mm}$ diameter filter paper (Grade 413, 5-13 $\mu \mathrm{m}$ particle retention, VWR International Ltd, Lutterworth, UK). The wet BC filter cake was carefully removed from the used filter paper and sandwiched between two fresh filter papers and six blotting papers (Grade 3MM CHR, GE Healthcare, Buckinghamshire, UK), followed by wet pressing under a weight of $10 \mathrm{~kg}$ for 10 min at room temperature to absorb excess water from the wet $\mathrm{BC}$ filter cake. This operation was repeated once more with fresh filter papers and blotting papers to further absorb the water from the BC filter cake. A final pressing step was then performed under a weight of 1 ton at an elevated temperature of $120^{\circ} \mathrm{C}$ for $30 \mathrm{~min}$ to dry and consolidate the $\mathrm{BC}$ filter cake into $\mathrm{BC}$ nanopaper. The $\mathrm{BC}$ nanopapers fabricated possessed a thickness of 46 $\pm 3 \mu \mathrm{m}$.

\subsection{Manufacturing of BC nanopaper-reinforced PLLA laminated composites}

A previous study of ours [22] showed high environmental burden associated with using vacuum assisted resin infusion (VARI) to produce BC nanopaper-reinforced composites, largely due to the need for consumables required the VARI process. Therefore in this work, 
film-stacking method was used to produce the laminated composites. BC nanopaperreinforced PLLA laminated composites consisting of (i) 1 sheet, (ii) 3 sheets, (iii) 6 sheets and (iv) 12 sheets of $\mathrm{BC}$ nanopaper, respectively, were fabricated. In order to attain high volume fraction of $\mathrm{BC}$ nanopaper(s) in the laminated composites, it is essential to use thin PLLA films [17]. To produce these, PLLA pellets were first dissolved in 1,4-dioxane at a mass ratio of $1: 12$ at $65{ }^{\circ} \mathrm{C}$ overnight under magnetic stirring. The polymer solution was then left to cool to room temperature prior to solution casted onto a glass plate using an automatic film applicator (Model 4340, Elcometer Ltd, Manchester, UK). After casting, 1,4-dixoane was left evaporated to produce PLLA film. The average thickness of the PLLA films produced was $10 \pm 3 \mu \mathrm{m}$.

BC nanopaper-reinforced PLLA laminated composites were fabricated by sandwiching the previously prepared BC nanopaper(s) with thin PLLA films following the stacking sequence shown in Fig. 1. A ceramic seam roller was used remove any air bubbles trapped between BC nanopaper and PLLA films. The BC nanopaper(s)-PLLA films lay-up was then sandwiched between two non-stick $125 \mu \mathrm{m}$ thick polyester release films (Mylar ${ }^{\circledR}$ A, Lohmann Adhesive Tape System, Milton Keynes, UK) secured onto steel plates using heat-resistant tape (Easy composites, Staffordshire, UK). The whole set up was pre-heated without pressing force to $180{ }^{\circ} \mathrm{C}$ for $3 \mathrm{~min}$ in a hydraulic press $(4122 \mathrm{CE}$, Carver Inc., Wabach, IN, USA). The pressing force of the hydraulic press was then increased to 0.5 ton at the same temperature for another 3 min to consolidate the BC nanopaper(s) and PLLA films into BC nanopaper-reinforced PLLA laminated composites. BC nanopaper-reinforced PLLA laminated composites consisting of 1, 3, 6 and 12 sheet(s) of $\mathrm{BC}$ nanopaper(s), are herein termed composite $\mathbf{1}$, composite $\mathbf{2}$, composite $\mathbf{3}$ and composite $\mathbf{4}$, respectively. The thicknesses of composites 1 to 4 were measured to be $60 \pm 5 \mu \mathrm{m}, 177 \pm 8 \mu \mathrm{m}, 382 \pm 21 \mu \mathrm{m}$ and $683 \pm 12$ $\mu \mathrm{m}$, respectively. These BC nanopaper-reinforced PLLA laminated composites possessed BC 
weight fraction $\left(w_{f}\right)$ of $69-75$ wt.- $\%$ based on simple mass gain measurements. All samples produced were annealed at $120^{\circ} \mathrm{C}$ for 30 min prior to subsequent characterisation.

\subsection{Characterisation of the BC nanopapers, neat PLLA and their PLLA laminated composites}

\subsubsection{Porosity of the BC nanopapers and the fabricated laminated composites}

He pycnometry (Accupyc II 1340, Micromeritics Ltd, Hexton, UK) was used to determine the true density of BC nanofibres $\left(\rho_{\mathrm{f}}\right)$ and neat PLLA $\left(\rho_{\mathrm{m}}\right)$. To determine the envelope density $\left(\rho_{\mathrm{e}}\right)$ of $\mathrm{BC}$ nanopaper and $\mathrm{BC}$ nanopaper-reinforced PLLA laminated composites, the thickness of the $\mathrm{BC}$ nanopaper and $\mathrm{BC}$ nanopaper-reinforced PLLA laminated composites was first measured using a digital micrometer (Mitutoyo MDC Lite, RS Components Ltd., Northants, UK) and $\rho_{\mathrm{e}}$ was calculated by taking the ratio between mass and envelop volume of the specimen. The porosity of the $\mathrm{BC}$ nanopaper $\left(P_{\mathrm{BC}}\right.$ nanopaper $)$ was then calculated using:

$P_{\mathrm{BC} \text { nanopaper }}(\%)=\left(1-\frac{\rho_{\mathrm{e}}}{\rho_{\mathrm{f}}}\right) \times 100$

To evaluate the porosity of the $\mathrm{BC}$ nanopaper-reinforced PLLA laminated composites, the theoretical (e.g. void free) density of the laminated composites $\left(\rho_{\mathrm{c}}\right)$ was first computed from the weight fraction of $\mathrm{BC}\left(w_{\mathrm{f}, \mathrm{BC}}\right)$ within the laminated composites:

$\rho_{\mathrm{c}}=\frac{1}{\frac{1-w_{\mathrm{f}, \mathrm{BC}}}{\rho_{\mathrm{m}}}+\frac{w_{\mathrm{f}, \mathrm{BC}}}{\rho_{\mathrm{f}}}}$

The porosity of the BC nanopaper-reinforced PLLA laminated composites $\left(P_{\text {composite }}\right)$ was then calculated using:

$P_{\text {composite }}(\%)=\left(1-\frac{\rho_{\mathrm{e}}}{\rho_{\mathrm{c}}}\right) \times 100$

\subsubsection{Tensile properties of $\mathrm{BC}$ nanopapers and the fabricated laminated composites}

Tensile test was conducted in accordance to BS EN ISO 527: 2012. Prior to the test, neat PLLA film, BC nanopapers and BC nanopaper-reinforced PLLA laminated composites were cut into miniaturised dog-bone shaped test specimens using a punch die (ZCP 020, Zwick 
Testing Machines Ltd, Herefordshire, UK). These miniaturised dog-bone shaped specimens possessed an overall length of $35 \mathrm{~mm}$, a gauge length of $10 \mathrm{~mm}$ and the narrowest part of the specimen has a width of $2 \mathrm{~mm}$. All test specimens were secured onto $140 \mathrm{~g} \mathrm{~m}^{-2}$ paper testing cards using a two-part cold curing epoxy resin (Araldite 2011, Huntsman Advanced Materials, UK) to avoid damages to the gripping area of the test specimens by the clamps of the tensile tester, potentially leading to an earlier onset failure within the gripping zone of the test specimens. Tensile test was performed using a micro-tensile tester (Model MT-200, Deben UK Ltd, Woolpit, UK) equipped with a $200 \mathrm{~N}$ load cell. Prior to the test, two points were marked on the surface of the test specimens in the direction of applied specimen displacement. The strain of the test specimens was evaluated by monitoring the movement of these two marked points using a non-contact video extensometer (iMetrum Ltd., Bristol, UK). All test specimens were loaded with a crosshead displacement speed of $0.5 \mathrm{~mm} \mathrm{~min}{ }^{-1}$ (corresponding to a test specimen strain rate of $0.05 \mathrm{~s}^{-1}$ ). Average results of 5 test specimens are reported for each sample.

\subsubsection{Gel permeation chromatography (GPC)}

GPC was used to investigate the molecular weight of PLLA. Neat PLLA and PLLA within the laminated composites were first dissolved at $1 \mathrm{mg}$ of PLLA per $\mathrm{mL}$ of HPLC grade chloroform at $60{ }^{\circ} \mathrm{C}$ for $24 \mathrm{~h}$. Samples were immersed in $3 \mathrm{~mL}$ of chloroform and the dissolved polymer extracted from the composite samples. The chloroform was then removed by rotary evaporation for 15 min prior to re-solubilising in HPLC grade THF (eluent phase for the GPC), at $1 \mathrm{mg} \mathrm{mL}^{-1}$, and filtered through a $0.45 \mu \mathrm{m}$ PTFE syringe filter. GPC analysis was performed using an Agilent 1260 infinity series HPLC with an online vacuum degasser, equipped with an Agilent online differential refractometer (DRI) and a Wyatt Helios Dawn 8 multi-angle light scattering detector (MALLS). Two Agilent $3 \mu \mathrm{m}$ PLgel Mixed C columns $(7.5 \times 300 \mathrm{~mm})$ were connected in series with an Agilent PLgel $3 \mu \mathrm{m}$ Guard column $(7.5 \times$ 
$50 \mathrm{~mm}$.) The column, DRI and MALLS temperature was set to $35^{\circ} \mathrm{C}$ and the flow rate set to $1 \mathrm{~mL}$ per minute, with sample injection volume set to $100 \mu \mathrm{L}$. The specific refractive index increment $(\mathrm{dn} / \mathrm{dc})$ of L-lactide and PLLA was set to $0.05 \mathrm{~mL} \mathrm{~g}^{-1}$. DRI calibration was performed using a $30 \mathrm{kDa}$ linear polystyrene narrow dispersity standard dissolved in THF at a concentration of $1.0 \mathrm{mg} \mathrm{mL}^{-1}$. MALLS calibration was performed using HPLC grade toluene, filtered through a $0.02 \mu \mathrm{m}$ PTFE filter and normalisation was performed in THF using a 30 kDa linear polystyrene narrow dispersity GPC calibration standard.

\subsubsection{Scanning electron microscopy (SEM)}

The internal morphology and microstructure of the non-fractured $\mathrm{BC}$ nanopaper-reinforced PLLA laminated composites were investigated using SEM (Hitachi S-3700N, Tokyo, Japan). The laminated composites were embedded in a two-part polyester resin (KLEER-SET, MetPrep Ltd., Coventry, UK) and polished (Saphir 550, Advanced Materialography, UK) using progressively finer sandpapers (P600 and P1200), followed by polishing cloth (first with polishing suspensions containing $0.3 \mu \mathrm{m}$ alumina, followed by $0.06 \mu \mathrm{m}$ silica suspensions). The polished polyester resin blocks containing the laminated composites were then mounted onto SEM stubs using carbon tabs, followed by Au coated (Agar Auto Sputter Coater, Essex, UK) at $40 \mathrm{~mA}$ for $40 \mathrm{~s}$ prior to SEM. The fracture surfaces of the $\mathrm{BC}$ nanopaper-reinforced PLLA laminated composites were also investigated using SEM. The specimens were mounted onto aluminium stubs using carbon tabs, followed by Au coating using the previously described coating current for $20 \mathrm{~s}$ prior to SEM.

\section{Results and Discussion}

\subsection{Porosity of BC nanopaper-reinforced PLLA laminated composites}

Table 1 summarises the porosity of BC nanopaper-PLLA laminated composites reinforced with 1, 3, 6 and 12 sheet(s) of BC nanopaper, along with the porosity of neat PLLA and BC nanopapers. The porosity of BC nanopaper fabricated in this work was found to be $33 \%$. This 
is consistent with a previous study by the authors [21]. A trend could also be observed for the porosity of BC nanopaper-reinforced PLLA laminated composites (table 1, composites 1 to 4). When PLLA was reinforced with one sheet of BC nanopaper, a laminated composite porosity of $\sim 17 \%$ was obtained. Increasing the number of reinforcing $\mathrm{BC}$ nanopaper to 3 sheets led to an increase in the porosity of the resulting laminated composites to $24 \%$. A further increase in the number of reinforcing BC nanopaper to 6 and 12 sheets, respectively, increased the porosity of the resulting laminated composites to $\sim 30 \%$. We have also estimated the theoretical porosity of the laminated composites $\left(P_{\text {theoretical }}\right)$ based on the porosity attained for $\mathrm{BC}$ nanopaper. Assuming that $\mathrm{BC}$ nanopaper sheets are uniform rectangular slabs that are incompressible and impermeable to molten PLLA, $P_{\text {theoretical }}$ can be estimated using:

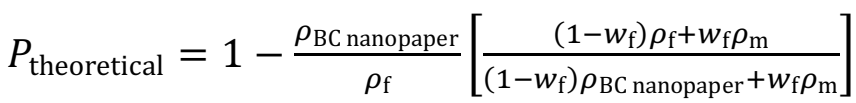

The $P_{\text {theoretical }}$ of laminated composites 1 to $\mathbf{4}$ was estimated to be $\sim 25 \%$ (see table 1). Composites 1 and $\mathbf{2}$ possess porosities lower than, or similar to, $P_{\text {theoretical }}$ while composites $\mathbf{3}$ and 4 possessed porosity values higher than $P_{\text {theoretical }}$. A measured porosity of lower than the $P_{\text {theoretical }}$ for composite $\mathbf{1}$ could be attributed to the degree of consolidation of a single sheet of BC nanopaper with PLLA. The measured porosities of higher than $P_{\text {theoretical }}$ for composites 3 and $\mathbf{4}$, on the other hand, could be attributed to the presence of scale-induced defects as the number of $\mathrm{BC}$ nanopaper sheets increases to 6 and 12 sheets, respectively. To further elucidate this deviation of porosity values of the laminated composites from theoretical values, we further investigated the internal morphology of our fabricated BC nanopaper-reinforced PLLA laminated composites.

\subsection{Internal morphology of BC nanopaper-reinforced PLLA laminated composites}


The polished cross-sections revealing the internal structure of the BC nanopaper-reinforced PLLA laminated composites are shown in Fig. 2a-d. ${ }^{\dagger}$ A multi-layer structure consisting of alternating layers of PLLA and BC nanopaper that are consistent with the stacking sequence used (see Fig. 1) can be observed, suggesting little or no impregnation of the $\mathrm{BC}$ nanopaper(s). This is attributed to the high viscosity of molten PLLA ( $>5000 \mathrm{~Pa}$ s at $\left.180{ }^{\circ} \mathrm{C}\right)$ [23] and the small pore size of the nanocellulose network [24]. In this context, the reinforcing effect of the laminated composites stems from BC nanopapers instead of individual BC nanofibres [14].

Figs. 2a-d also show the presence of various defects in the laminated composites. Three types of defects were observed; thickness inhomogeneity and out-of-plane waviness of BC nanopaper(s) in the laminated composites, voids between adjacent layers of $\mathrm{BC}$ nanopaper (see dotted circles in Fig. 2d) and micro-cracks within the BC nanopaper (see dotted arrows). The thickness inhomogeneity and out-of-plane waviness of BC nanopaper can be ascribed to the formation of aggregates/bundles of $\mathrm{BC}$ in the starting $\mathrm{BC}$-in-water suspension, which was due to difficulties in disrupting the 3-dimensional network of $\mathrm{BC}$ pellicles with low energy blending [21]. As a result of the BC aggregates in the suspension, the formation of $\mathrm{BC}$ network within the $\mathrm{BC}$ nanopaper is non-uniform, leading to the observed thickness inhomogeneity and waviness of the $\mathrm{BC}$ nanopaper. Voids between adjacent $\mathrm{BC}$ nanopapers are also observed in composite 4, which consists of 12 sheets of reinforcing $\mathrm{BC}$ nanopaper. The origin of these voids can be attributed to air bubbles trapped during the laying up of composite 4. The large number of layers in composite 4 (12 sheets of BC nanopaper and 13 layers of PLLA) and the short consolidation time led to difficulties in removing the trapped air bubbles between the layers of PLLA and BC nanopaper.

\footnotetext{
$\uparrow$ More SEM images showing the internal morphology of the BC nanopaper-reinforced PLLA laminated composites at various laminated composite depths can be found in the supplementary information.
} 
To ascertain whether micro-cracks are present in the starting BC nanopaper, we have also investigated the internal morphology of neat BC nanopaper (Fig. 2e). Micro-cracks could also be observed in the nanopaper (see arrow, Fig. 2e). The formation of micro-cracks in neat $\mathrm{BC}$ nanopaper is hypothesised to be due to the residual stress formed during the drying of wet $\mathrm{BC}$ filter cake to produce the $\mathrm{BC}$ nanopaper. When conventional paper dries, the surface layers contract and the material in the centre comply. This difference in the response of the neighbouring materials during this contraction would lead to the formation of residual stress in conventional paper [25]. We postulate that a similar effect occurred in our BC nanopaper. In the heat consolidation step, our partially dried BC filter cake was sandwiched between two filter papers and heat pressed. This was to prevent the lateral contraction of the filter cake by restraining the $\mathrm{BC}$ filter cake onto filter papers during drying. While lateral contraction of the $\mathrm{BC}$ filter cake was prevented, the contraction and shrinking in the through-thickness direction still occurred as the moisture ratio of the filter cake decreased. Since the outer layers of the $\mathrm{BC}$ filter cake were restrained onto the filter papers during drying, it is anticipated the drier outer layers compared to the swollen wet core, coupled with the non-uniform formation of the $\mathrm{BC}$ network in the nanopaper led to the formation of micro-cracks in the $\mathrm{BC}$ nanopaper.

It could also be observed from Figs. 2a-d that the presence and severity of microcracks in the reinforcing $\mathrm{BC}$ nanopaper increased with $\mathrm{BC}$ nanopaper sheets in the laminated composites. As the BC nanopaper-PLLA laminate consolidates under heat and an external pressing force, the molten PLLA in between adjacent sheets of $\mathrm{BC}$ nanopaper or between $\mathrm{BC}$ nanopaper and the non-stick release film will start to flow. It has been shown that the slip length (a measure of the degree of slip of an interface) of a polymer on a flat and weakly interacting surface is higher than a rough and corrugated surface [26]. This implies that molten PLLA will slip easily along the non-stick release film surface during heat consolidation and conform to the waviness of $\mathrm{BC}$ nanopaper, as observed in composite $\mathbf{1}$. As 
a result, the severity and presence of defects are low for $\mathrm{BC}$ nanopaper-PLLA laminate reinforced with one sheet of $\mathrm{BC}$ nanopaper. This is also consistent with the absence of severe micro-cracks in the BC nanopapers at the top and bottom layers of composites 2 to 4 . The slip length between molten PLLA and BC nanopaper, on the other hand, is anticipated to be low (e.g. low degree of slip) due to the rough $\mathrm{BC}$ nanopaper surface. As a result, the flow of molten PLLA between two adjacent BC nanopapers led to the delamination the nanopapers during heat consolidation. This situation is further accentuated by the inhomogeneity and waviness of $\mathrm{BC}$ nanopaper, with regions of non-uniform areal density of $\mathrm{BC}$ in the nanopaper. Consequently, the severity and presence of micro-cracks in the $\mathrm{BC}$ nanopaper at the mid-plane of the laminated composites with $\geq 3$ sheets of $\mathrm{BC}$ nanopaper were high and increased with the number of sheets of BC nanopaper in the laminated composites. Similar effects have also been observed in the consolidation of carbon fibre-reinforced polymer laminates [27].

\subsection{Tensile properties of the neat PLLA, BC nanopaper and their laminated}

\section{composites}

The tensile properties of neat PLLA, BC nanopaper and their laminated composites are summarised in Table 2 and a comparison of tensile properties between the single sheet $\mathrm{BC}$ nanopaper- or BC pellicle-reinforced polymer composites fabricated by various authors and composites fabricated in this work is summarised in Table 3. BC nanopaper was found to possess tensile modulus $(E)$ and strength $\left(\sigma_{\max }\right)$ of $\sim 15 \mathrm{GPa}$ and $\sim 140 \mathrm{MPa}$, respectively. These values are consistent with values obtained by other researchers [21]. By reinforcing PLLA with BC nanopaper(s) at BC volume fraction $\left(v_{\mathrm{f}, \mathrm{BC}}\right)$ of $65-72$ vol.- $\%$, tensile moduli of $12.4-13.6 \mathrm{GPa}$ were obtained. The slight variation in the measured tensile modulus of the laminated composites is attributed to the slight variations of $v_{\mathrm{f}, \mathrm{BC}}$. Higher $v_{\mathrm{f}, \mathrm{BC}}$ leads to

higher measured $E$. Our results also suggest that the measured $E$ is relatively independent of 
porosity and the number of reinforcing $\mathrm{BC}$ nanopapers in the laminated composites. This could be due to the fact that for elastic modulus, the point-to-point variations at small scales will be averaged out over the volume of the specimens tested as the porosity of the composites in our study do not differ significantly from each other [28].

Unlike the measured $E$ of the BC nanopaper-reinforced PLLA laminated composites, a knockdown effect can be observed for the measured $\sigma_{\max }$ of the laminated composites. The tensile strength decreases consistently from $121 \mathrm{MPa}$ for laminated composites reinforced with 1 sheet of $\mathrm{BC}$ nanopaper (composite 1) to only $95 \mathrm{MPa}$ for laminated composites reinforced with 12 sheets of BC nanopaper (composite 4). This decrease in tensile strength of the laminated composites could be explained by the weakest link theory: failure initiate from a flaw within the material [29]. As observed in Fig. 2, the severity of the micro-cracks increases with increasing number of sheets of $\mathrm{BC}$ nanopaper in the laminated composites. These micro-cracks acted as flaws, leading to early onset failure of the laminated composites. As a result, composite 4 possessed the lowest $\sigma_{\max }$ due to the presence of a large number of micro-cracks.

Increasing the number of reinforcing $\mathrm{BC}$ nanopaper within the laminated composites also has an impact on the molecular weight of PLLA. BC nanopaper is hydrophilic and simple weight gain measurements showed that BC nanopaper possessed a moisture content of 2 wt.-\%. As a result, hydrolytic degradation of PLLA [30] occurred as the number of reinforcing BC nanopaper sheets increased. This is further confirmed by GPC (see Table 2). Significant reduction in the weight-averaged molecular weight $\left(M_{\mathrm{w}}\right)$ of PLLA was observed for composite 4 compared to neat PLLA but no significant difference in $M_{\mathrm{w}}$ was observed between neat PLLA and composites 1-3. This is due to the large number of reinforcing BC nanopaper (12 sheets of BC nanopaper) used in composite 4. 
The representative stress-strain curves for PLLA, BC nanopaper and each type of laminated composite fabricated in this work are shown in Fig. 3. The stress-strain curve of $\mathrm{BC}$ nanopaper comprised of an initial elastic behaviour, followed by an inelastic deformation prior to catastrophic fracture at a strain-to-failure $(\varepsilon)$ of $\sim 3 \%$. PLLA, on the other hand, failed in a brittle manner at $\varepsilon=2 \%$. The stress-strain curves of composites $\mathbf{1}$ to $\mathbf{3}$ showed a catastrophic failure when peak loads were reached while composite 4, which contained 12 sheets of BC nanopaper, showed a progressive failure. When peak load was reached for composite 4, one (or more) BC nanopaper(s) fractured from the micro-cracks present and the load (which was lower than loads sustained by composites $\mathbf{1}$ to $\mathbf{3}$ at the point of fracture) was transferred locally to surrounding BC nanopapers that could still sustain the load exerted on the specimen, leading to the observed progressive failure of the stress-strain curve.

\subsection{Fracture surfaces of BC nanopaper-reinforced PLLA laminated composites}

The fracture surfaces of composites 1 to $\mathbf{4}$, which provides further information on the influence of number of sheet(s) of $\mathrm{BC}$ nanopaper in the laminated composites, are shown in Fig. 4. In all cases, significant defibrillation was observed for $\mathrm{BC}$ nanopapers and the presence of ribbons and scraps on the fracture surface of the PLLA is indicative of a brittle fracture [31], which also corroborate with the stress-strain curve of PLLA. Composite 1 exhibited a localised fracture surface while composites $\mathbf{2}$ to $\mathbf{4}$ showed more extensive fracturing throughout the specimen. Such extensive fracturing process is consistent with the presence of micro-cracks in the reinforcing $\mathrm{BC}$ nanopapers.

When peak load is reached, micro-cracks within the BC nanopaper will start to propagate and coalesce forming larger cracks [32], which ultimately led to the fracture of the BC nanopaper. Composite 1 was reinforced only with one sheet of BC nanopaper. The fracture of $\mathrm{BC}$ nanopaper in composite 1 will lead to the fracture of the composite, leading to a more localised fracture. Composites 2 to 4 were reinforced with more than one sheet of BC 
nanopaper. When a $\mathrm{BC}$ nanopaper fractures, the load is transferred to surrounding intact $\mathrm{BC}$ nanopapers, and caused the micro-cracks (which might not be on the same plane) in the nearby $\mathrm{BC}$ nanopapers to start propagate, leading to the observed extensive fracturing process.

It is also worth noting that the de-bonding of BC nanopaper/PLLA interface was not observed. Similar observation was also obtained for BC pellicle-reinforced PLLA composites [33]. Direct wetting measurements showed that the contact angle of PLLA droplet on a single $\mathrm{BC}$ nanofibre was found to be $35.4 \pm 0.8^{\circ}$. This results suggest good thermodynamic adhesion between BC and PLLA [34]. Therefore, the fracture process of BC nanopaperreinforced PLLA laminated composites is governed by the fracture process of $\mathrm{BC}$ nanopaper within the laminated composites instead of the BC nanopaper/PLLA interface.

\section{Concluding remarks}

The mechanical response of BC nanopaper-reinforced PLLA laminated composites as a function of number of reinforcing $\mathrm{BC}$ nanopaper sheets have been studied in this work. It was found that by increasing the number of reinforcing BC nanopapers from 1 sheet to 12 sheets, the porosity of the resulting BC nanopaper-reinforced PLLA laminated composites increased from $17 \%$ (laminated composites reinforced with 1 sheet of BC nanopaper) to $\sim 30 \%$ (laminated composites reinforced with 12 sheets of BC nanopapers). The tensile moduli of the laminated composites were found to be $\sim 12.4-13.6 \mathrm{GPa}$ (at $v_{\mathrm{f}, \mathrm{BC}}=65-72$ vol.- $\%$ ), insensitive to the number of reinforcing BC nanopaper sheets in the laminated composites. However, the tensile strength of the laminated composites decreased by up to $25 \%$ from 121 MPa for PLLA laminated composites reinforced with 1 and 3 sheets of BC nanopaper(s) to only $95 \mathrm{MPa}$ for laminated composites reinforced with 12 sheets of BC nanopapers. Fractographic analysis also showed that laminated composites reinforced with more than $\geq 3$ 
sheets of BC nanopaper exhibited an extensive fracture of the test specimens while composites reinforced with only 1 sheet of BC nanopaper showed a localised fracture.

We attribute these observations to the presence of scale-induced defects as the number of sheets of reinforcing $\mathrm{BC}$ nanopaper increased. As the number of reinforcing $\mathrm{BC}$ nanopaper sheets increased, it was also observed that the presence and severity of these defects increased. Three types of defects have been observed in the BC nanopaper-PLLA laminated composites; (i) thickness inhomogeneity and out-of-plane waviness of BC nanopaper(s) in the laminated composites, which is a result of the formation of aggregates/bundles in the starting BC-in-water suspension prior to nanopaper manufacturing, (ii) voids between adjacent layers of $\mathrm{BC}$ nanopapers, which originated from air bubbles trapped during the layup of large number of sheets of BC nanopaper and difficulties in removing them as the lay-up was too thick, and (iii) micro-cracks within the BC nanopapers, which is attributed to the formation of residual stress during the drying of $\mathrm{BC}$ nanopapers. The presence and severity of these micro-cracks in the $\mathrm{BC}$ nanopapers were hypothesised to be accentuated during the consolidation step to produce PLLA laminated composites reinforced with multi-layers of BC nanopaper.

\section{Acknowledgement}

The authors would like to thank the UK Engineering and Physical Science Research Council (EPSRC) for funding this work (EP/M012247/1) and Department of Aeronautics, Imperial College London for funding MH.

\section{References}

[1] Lee KY, Buldum G, Mantalaris A, Bismarck A. More than meets the eye in bacterial cellulose: biosynthesis, bioprocessing, and applications in advanced fiber composites. Macromol Biosci 2014;14:10-32. doi:10.1002/mabi.201300298.

[2] Klemm D, Kramer F, Moritz S, Lindstrom T, Ankerfors M, Gray D, et al. Nanocelluloses: a new family of nature-based materials. Angew Chem Int Ed Engl 2011;50:5438-66. doi:10.1002/anie.201001273. 
[3] Lahtinen P, Liukkonen S, Pere J, Sneck A, Kangas H. A comparative study of fibrillated fibers from different mechanical and chemical pulps. BioResources 2014;9:2115-27. doi:10.15376/biores.9.2.2115-2127.

[4] VanderHart DL, Atalla RH. Studies of microstructure in native celluloses using solidstate carbon-13 NMR. Macromolecules 1984;17:1465-72. doi:10.1021/ma00138a009.

[5] Mangayil R, Rajala S, Pammo A, Sarlin E, Luo J, Santala V, et al. Engineering and Characterization of Bacterial Nanocellulose Films as Low Cost and Flexible Sensor Material. ACS Appl Mater Interfaces 2017;9:19048-56. doi:10.1021/acsami.7b04927.

[6] Guhados G, Wan WK, Hutter JL. Measurement of the elastic modulus of single bacterial cellulose fibers using atomic force microscopy. Langmuir 2005;21:6642-6. doi:10.1021/La0504311.

[7] Hsieh YC, Yano H, Nogi M, Eichhorn SJ. An estimation of the Young's modulus of bacterial cellulose filaments. Cellulose 2008;15:507-13. doi:10.1007/s10570-008-92068.

[8] Lee K-Y, Wong LLC, Blaker JJ, Hodgkinson JM, Bismarck A. Bio-based macroporous polymer nanocomposites made by mechanical frothing of acrylated epoxidised soybean oil. Green Chem 2011;13:3117-23. doi:10.1039/C1GC15655A.

[9] Sousa AF, Ferreira S, Lopez A, Borges I, Pinto RJB, Silvestre AJD, et al. Thermosetting AESO-bacterial cellulose nanocomposite foams with tailored mechanical properties obtained by Pickering emulsion templating. Polymer 2017;118:127-34. doi:10.1016/j.polymer.2017.04.073.

[10] Fortea-Verdejo M, Lee K-Y, Zimmermann T, Bismarck A. Upgrading flax nonwovens: Nanocellulose as binder to produce rigid and robust flax fibre preforms. Compos Part Appl Sci Manuf 2016;83:63-71. doi:10.1016/j.compositesa.2015.11.021.

[11] Juntaro J, Pommet M, Kalinka G, Mantalaris A, Shaffer MSP, Bismarck A. Creating Hierarchical Structures in Renewable Composites by Attaching Bacterial Cellulose onto Sisal Fibers. Adv Mater 2008;20:3122-6. doi:10.1002/adma.200703176.

[12] Shah N, Ul-Islam M, Khattak WA, Park JK. Overview of bacterial cellulose composites: A multipurpose advanced material. Carbohydr Polym 2013;98:1585-98. doi:10.1016/j.carbpol.2013.08.018.

[13] Ul-Islam M, Khan S, Ullah MW, Park JK. Bacterial cellulose composites: Synthetic strategies and multiple applications in bio-medical and electro-conductive fields. Biotechnol J 2015;10:1847-61. doi:10.1002/biot.201500106.

[14] Lee K-Y, Aitomäki Y, Berglund LA, Oksman K, Bismarck A. On the use of nanocellulose as reinforcement in polymer matrix composites. Compos Sci Technol 2014;105:15-27. doi:10.1016/j.compscitech.2014.08.032.

[15] Gindl W, Keckes J. Tensile properties of cellulose acetate butyrate composites reinforced with bacterial cellulose. Compos Sci Technol 2004;64:2407-13. doi:10.1016/j.compscitech.2004.05.001.

[16] Yano H, Sugiyama J, Nakagaito AN, Nogi M, Matsuura T, Hikita M, et al. Optically transparent composites reinforced with networks of bacterial nanofibers. Adv Mater 2005;17:153-5. doi:10.1002/adma.200400597.

[17] Montrikittiphant T, Tang M, Lee KY, Williams CK, Bismarck A. Bacterial cellulose nanopaper as reinforcement for polylactide composites: renewable thermoplastic nanopapreg. Macromol Rapid Commun 2014;35:1640-5. doi:10.1002/marc.201400181.

[18] Juntaro J, Ummartyotin S, Sain M, Manuspiya H. Bacterial cellulose reinforced polyurethane-based resin nanocomposite: A study of how ethanol and processing pressure affect physical, mechanical and dielectric properties. Carbohydr Polym 2012;87:2464-9. doi:10.1016/j.carbpol.2011.11.020. 
[19] Lee K-Y, Tammelin T, Schulfter K, Kiiskinen H, Samela J, Bismarck A. High performance cellulose nanocomposites: comparing the reinforcing ability of bacterial cellulose and nanofibrillated cellulose. ACS Appl Mater Interfaces 2012;4:4078-86. doi:10.1021/am300852a.

[20] Amacher R, Cugnoni J, Botsis J, Sorensen L, Smith W, Dransfeld C. Thin ply composites: Experimental characterization and modeling of size-effects. Compos Sci Technol 2014;101:121-32. doi:10.1016/j.compscitech.2014.06.027.

[21] Hervy M, Santmarti A, Lahtinen P, Tammelin T, Lee K-Y. Sample geometry dependency on the measured tensile properties of cellulose nanopapers. Mater Des n.d. doi:10.1016/j.matdes.2017.02.081.

[22] Hervy M, Evangelisti S, Lettieri P, Lee K-Y. Life cycle assessment of nanocellulosereinforced advanced fibre composites. Compos Sci Technol 2015;118:154-62. doi:10.1016/j.compscitech.2015.08.024.

[23] Lehermeier HJ, Dorgan JR. Melt rheology of poly(lactic acid): Consequences of blending chain architectures. Polym Eng Sci 2001;41:2172-84. doi:10.1002/pen.10912.

[24] Orsolini P, Michen B, Huch A, Tingaut P, Caseri WR, Zimmermann T. Characterization of pores in dense nanopapers and nanofibrillated cellulose membranes: a critical assessment of established methods. ACS Appl Mater Interfaces 2015;7:25884-97. doi:10.1021/acsami.5b08308.

[25] Östlund M, Östlund S, Carlsson L, Fellers C. The influence of drying restraints and beating degree on residual stress build-up in paperboard. J Pulp Pap Sci JPPS 2004;30:289-93.

[26] Niavarani A, Priezjev NV. Rheological study of polymer flow past rough surfaces with slip boundary conditions. J Chem Phys 2008;129:144902. doi:10.1063/1.2988496.

[27] Dodwell TJ, Butler R, Hunt GW. Out-of-plane ply wrinkling defects during consolidation over an external radius. Compos Sci Technol 2014;105:151-9. doi:10.1016/j.compscitech.2014.10.007.

[28] Wisnom MR. Size effects in the testing of fibre-composite materials. Compos Sci Technol 1999;59:1937-57. doi:10.1016/S0266-3538(99)00053-6.

[29] Freudenthal AM. Fatigue and fracture mechanics. Institute for the Study of Fatigue, Fracture and Structural Reliability, George Washington Univ.; 1972.

[30] Elsawy MA, Kim K-H, Park J-W, Deep A. Hydrolytic degradation of polylactic acid (PLA) and its composites. Renew Sustain Energy Rev 2017;79:1346-52. doi:10.1016/j.rser.2017.05.143.

[31] Greenhalgh ES. Failure Analysis and Fractography of Polymer Composites. Woodhead Publishing Ltd; 2009.

[32] Perkins WG. Polymer toughness and impact resistance. Polym Eng Sci 1999;39:244560. doi:10.1002/pen.11632.

[33] Quero F, Nogi M, Yano H, Abdulsalami K, Holmes SM, Sakakini BH, et al. Optimization of the Mechanical Performance of Bacterial Cellulose/Poly(1-lactic) Acid Composites. ACS Appl Mater Interfaces 2010;2:321-30. doi:10.1021/am900817f.

[34] Lee K-Y, Blaker JJ, Bismarck A. Surface functionalisation of bacterial cellulose as the route to produce green polylactide nanocomposites with improved properties. Compos Sci Technol 2009;69:2724-33. doi:10.1016/j.compscitech.2009.08.016.

[35] Kunjalukkal Padmanabhan S, Esposito Corcione C, Nisi R, Maffezzoli A, Licciulli A. PolyDiethyleneglycol-bisallyl carbonate matrix transparent nanocomposites reinforced with bacterial cellulose microfibrils. Eur Polym J 2017;93:192-9. doi:10.1016/j.eurpolymj.2017.05.037.

[36] Pinto ERP, Barud HS, Silva RR, Palmieri M, Polito WL, Calil VL, et al. Transparent composites prepared from bacterial cellulose and castor oil based polyurethane as 
substrates for flexible OLEDs. J Mater Chem C 2015;3:11581-8. doi:10.1039/C5TC02359A.

[37] Retegi A, Algar I, Martin L, Altuna F, Stefani P, Zuluaga R, et al. Sustainable optically transparent composites based on epoxidized soy-bean oil (ESO) matrix and high contents of bacterial cellulose (BC). Cellulose 2012;19:103-9. doi:10.1007/s10570-0119598-8.

[38] Lee K-Y, Bismarck A. Chapter 6 - Bacterial NanoCellulose as Reinforcement for Polymer Matrices. In: Gama M, Dourado F, Bielecki S, editors. Bact. Nanocellulose, Amsterdam: Elsevier; 2016, p. 109-22. doi:10.1016/B978-0-444-63458-0.00006-8. 


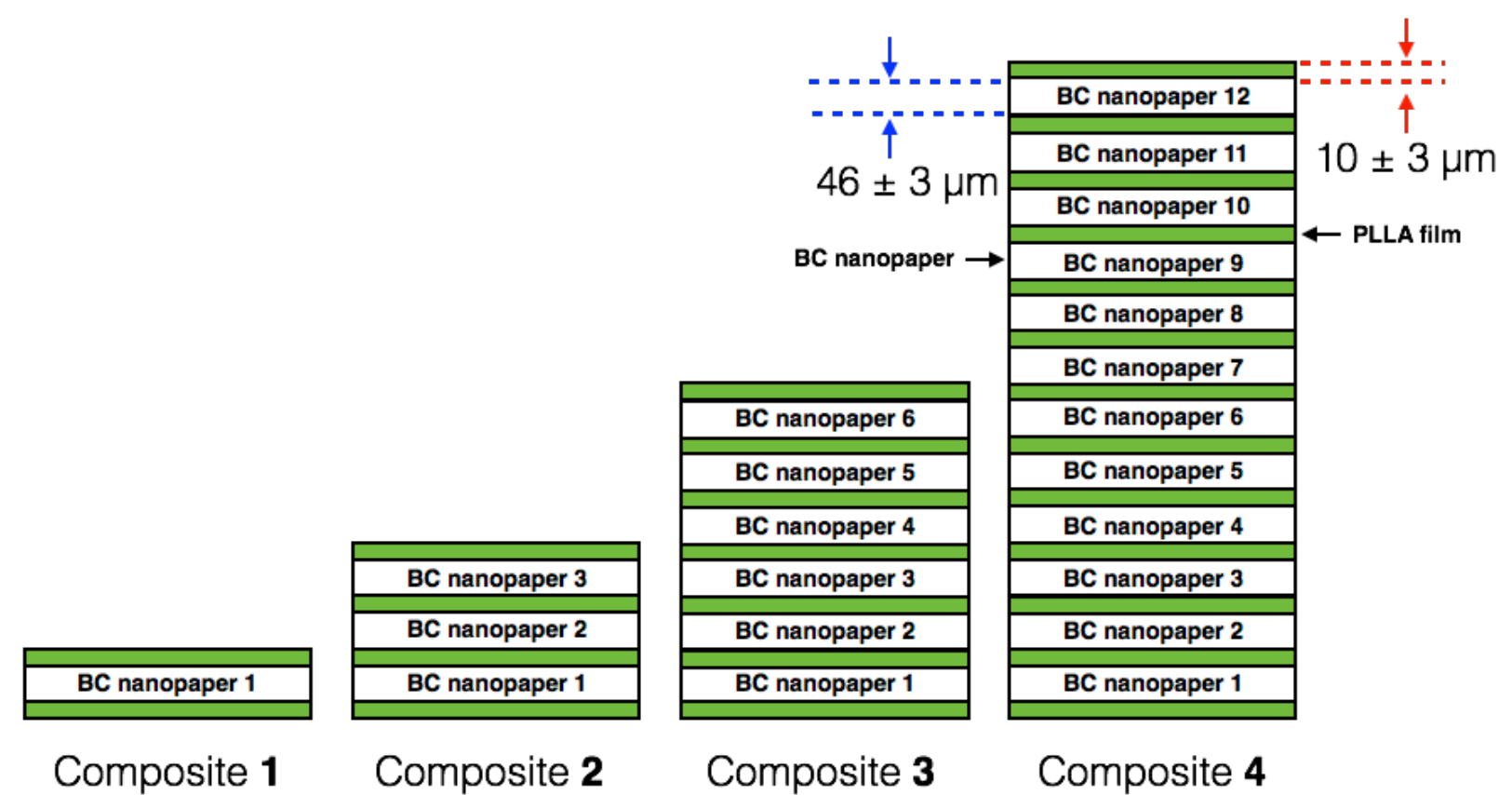

Figure 1: Stacking sequence of BC nanopaper-reinforced PLLA laminated composites fabricated in this work. 

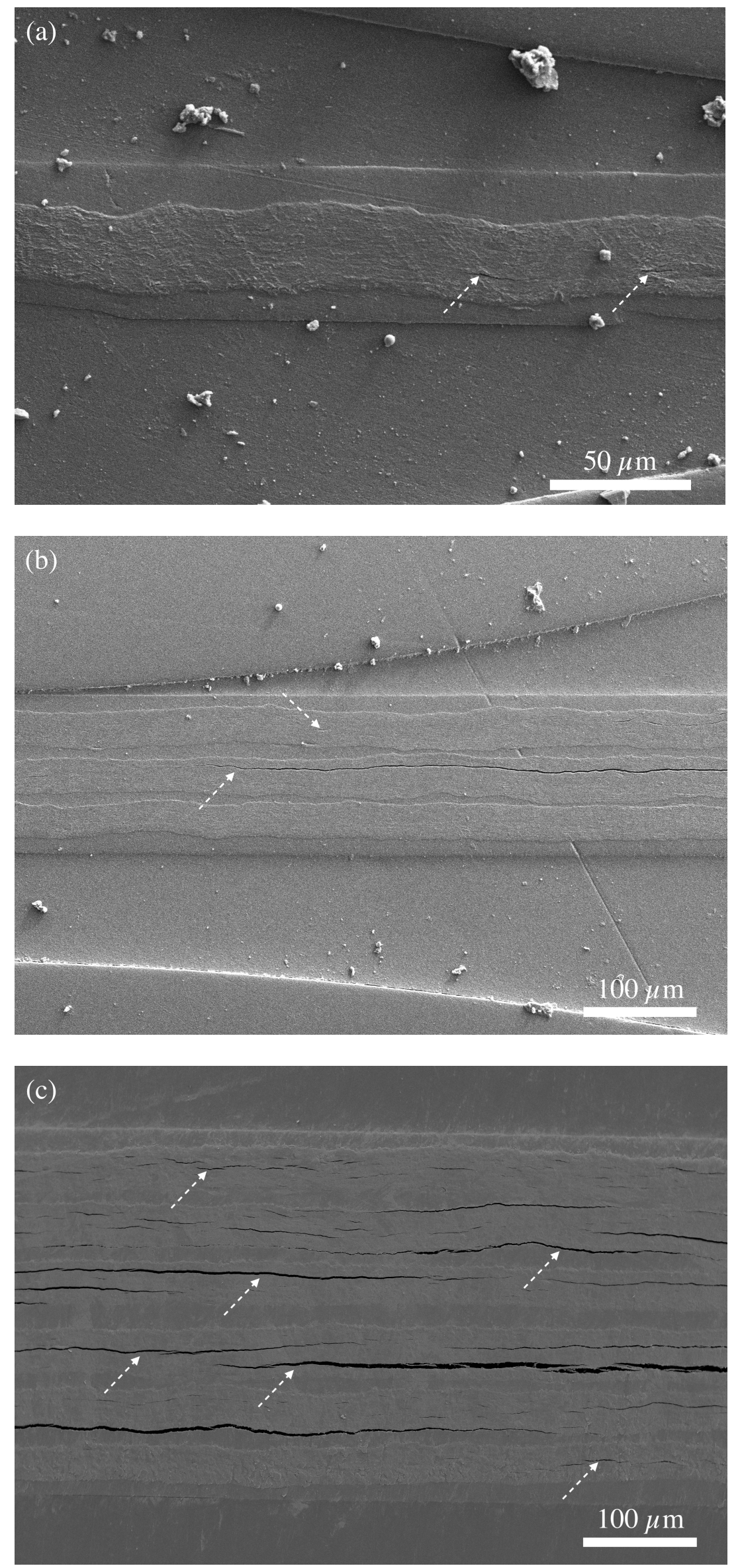

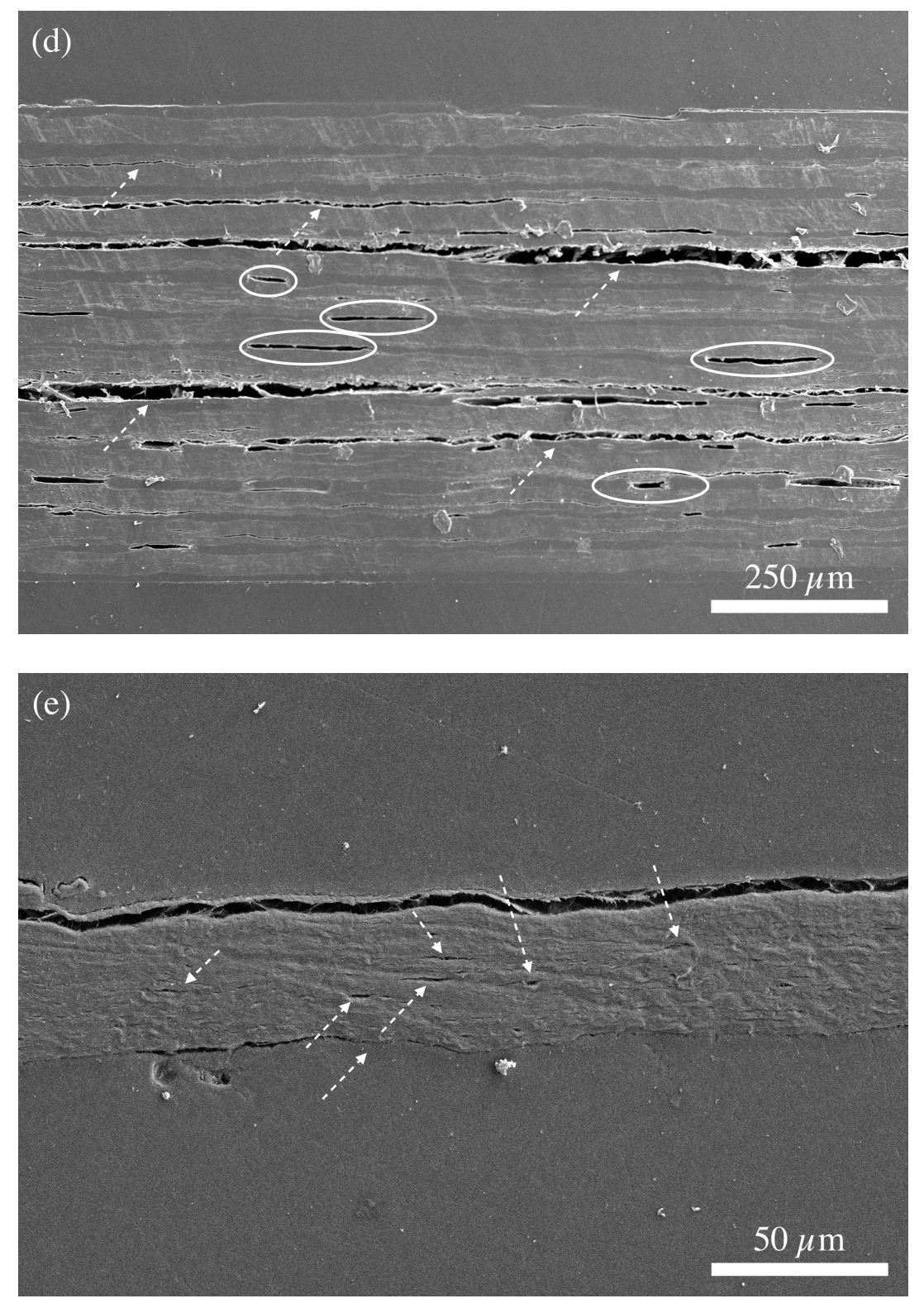

Figure 2: Polished cross-sections of the BC nanopaper-reinforced PLLA laminated composites and BC nanopaper. (a) Composite 1, (b) Composite 2, (c) Composite 3, (d) Composite 4, (e) BC nanopaper. The dotted arrows show the presence of micro-cracks in the reinforcing BC nanopaper. The circles show the voids in composite 4. 


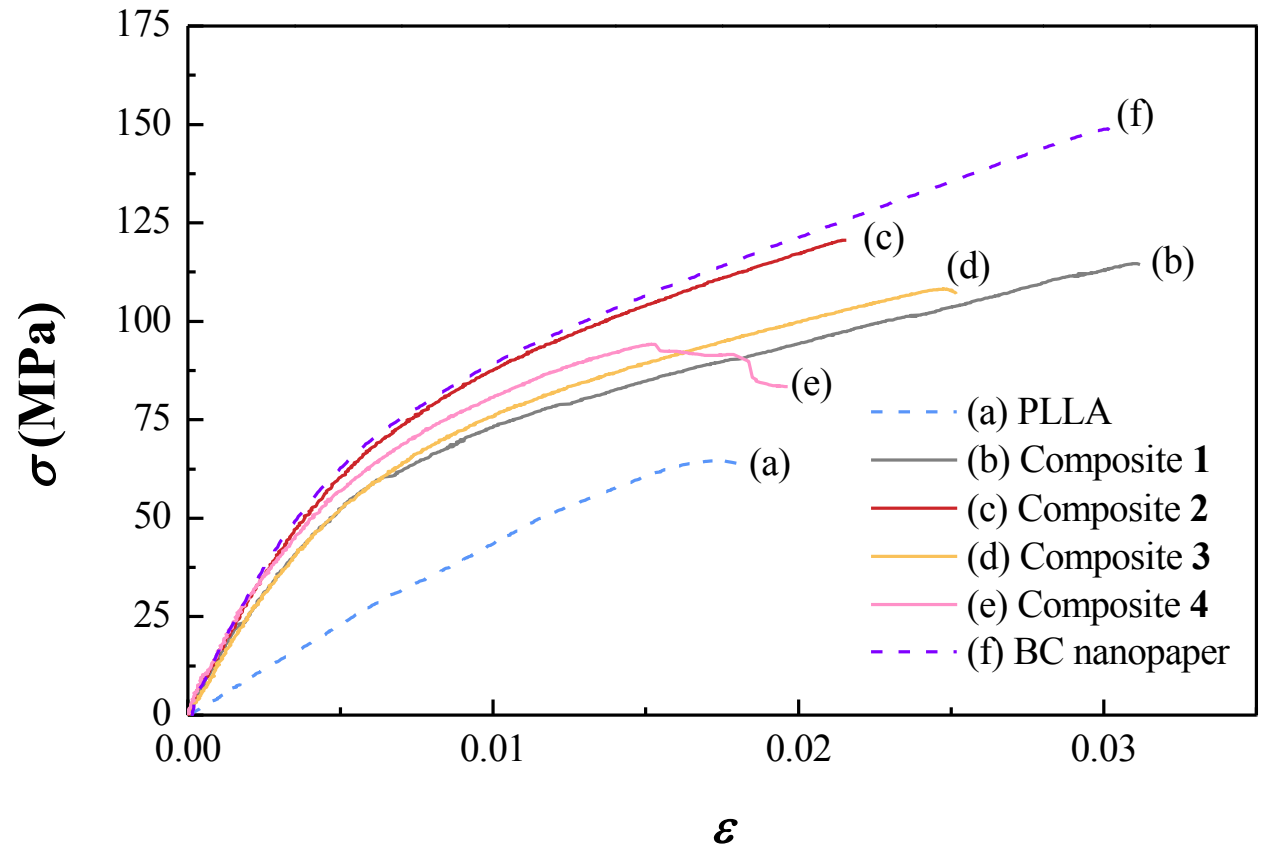

Figure 3: Representative stress-strain curves obtained for the neat PLLA, BC nanopaper and the fabricated laminated composites 

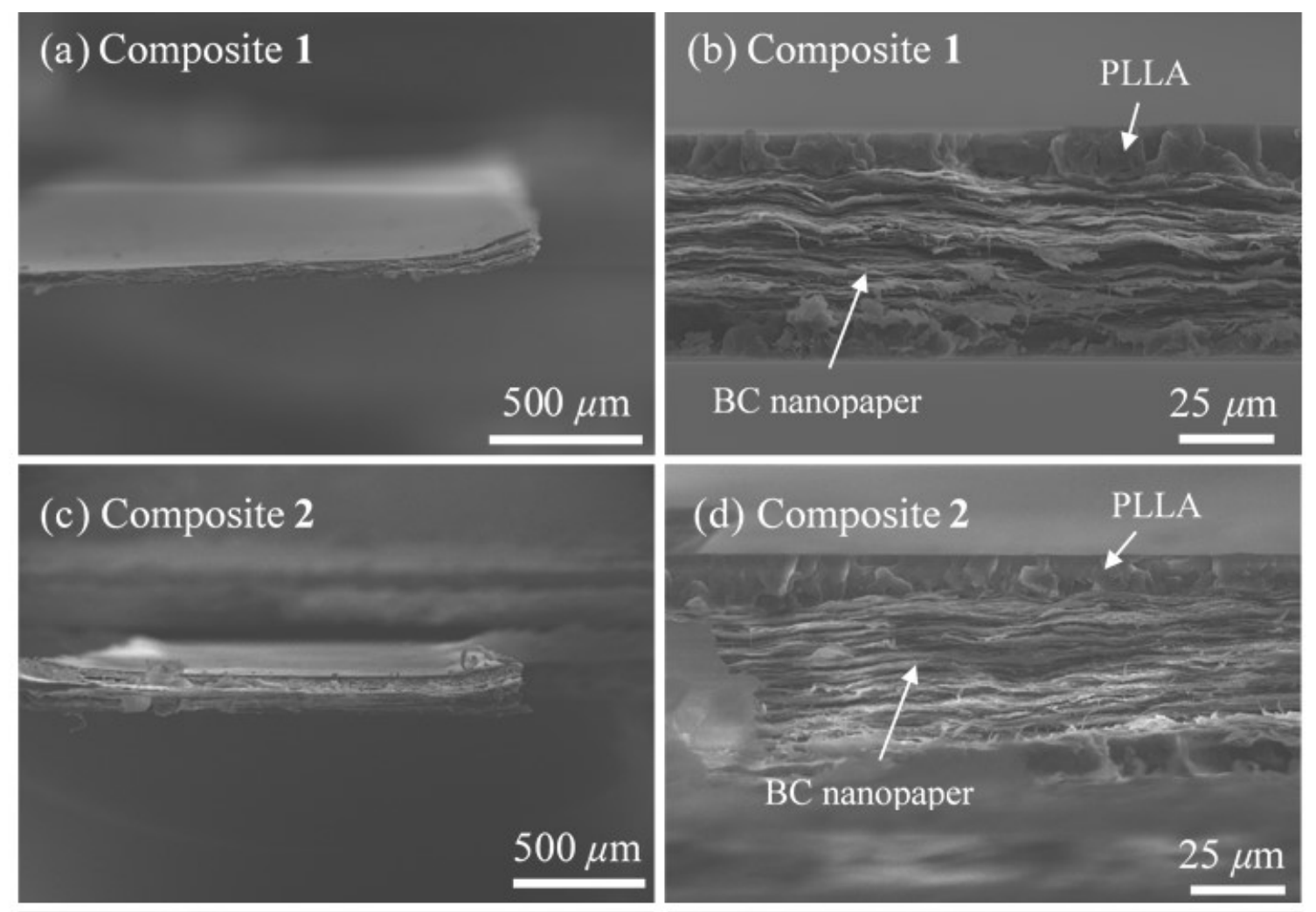

\section{(e) Composite 3}
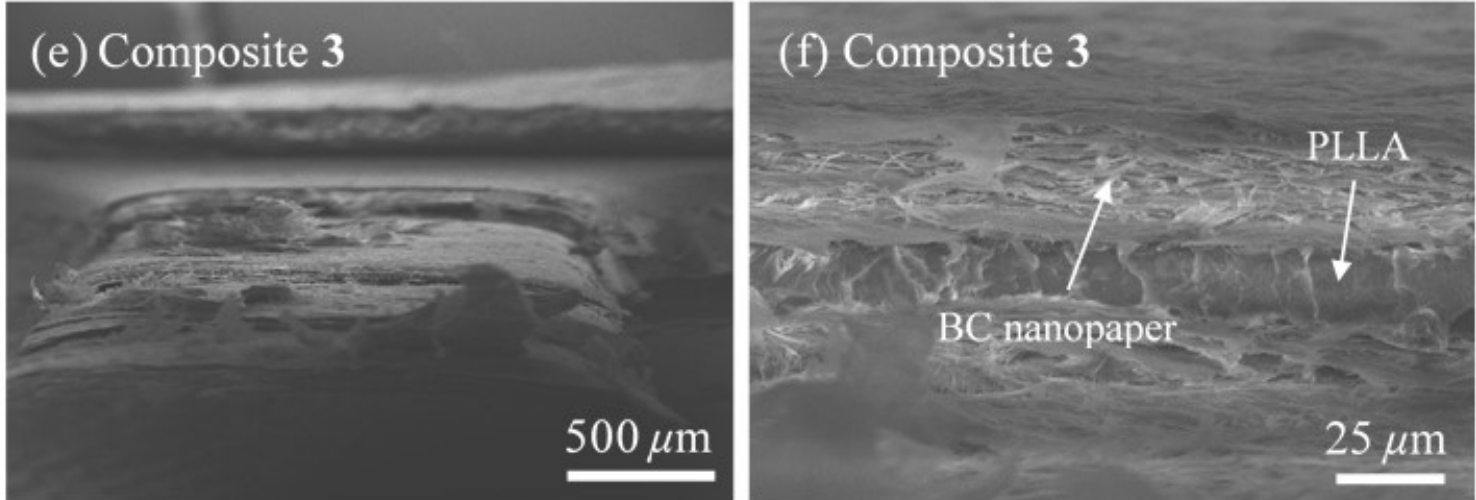

(g) Composite 4
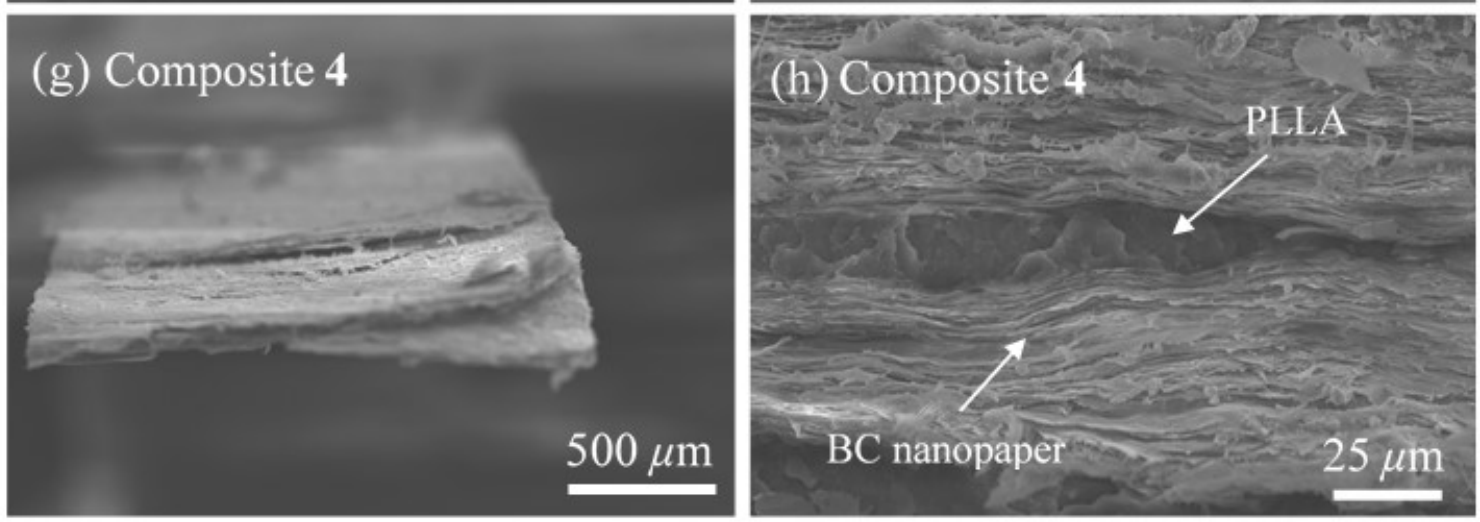

Figure 4: Fracture surfaces of the laminated composites at low magnification (Fig. 4a, c, e, g) and high magnification (Fig. 4b, d, f, g), respectively. 
Table 1: The density and porosity of neat PLLA, BC nanopaper and laminated composites. $\rho_{\mathrm{e}}, \rho$ and $P$ denote the envelope density, true/theoretical density and porosity, respectively.

\begin{tabular}{lccll}
\hline Sample & $\rho_{\mathrm{e}}\left(\mathrm{g} \mathrm{cm}^{-3}\right)$ & $\rho^{\S}\left(\mathrm{g} \mathrm{cm}^{-3}\right)$ & $P(\%)$ & $P_{\text {theoretical }}(\%)$ \\
\hline PLLA & $1.26 \pm 0.01$ & $1.26 \pm 0.01$ & 0 & \\
Composite 1 & $1.17 \pm 0.09$ & $1.42 \pm 0.01$ & $17 \pm 1$ & $25 \pm 1$ \\
Composite 2 & $1.09 \pm 0.05$ & $1.43 \pm 0.01$ & $24 \pm 1$ & $26 \pm 1$ \\
Composite 3 & $0.98 \pm 0.05$ & $1.42 \pm 0.01$ & $31 \pm 2$ & $25 \pm 1$ \\
Composite 4 & $1.00 \pm 0.02$ & $1.44 \pm 0.01$ & $30 \pm 1$ & $26 \pm 1$ \\
BC nanopaper & $1.00 \pm 0.07$ & $1.51 \pm 0.01$ & $33 \pm 1$ &
\end{tabular}

${ }_{\S}^{\S}$ obtained using He pycnometry for neat PLLA and BC nanopaper, and calculated using equation 2 for the laminated composites.

Table 2: The tensile properties of neat PLLA, BC nanopaper and their laminated composites. $v_{\mathrm{f}, \mathrm{BC}}, E, \sigma_{\max }, \varepsilon$ and $M_{\mathrm{w}}$ denote the fibre volume fraction of $\mathrm{BC}$ within the laminated composites, tensile modulus, tensile strength, strain-to-failure and molecular weight of PLLA, respectively.

\begin{tabular}{llllll}
\hline Sample & $v_{\mathrm{f}, \mathrm{BC}}(\%)$ & $E(\mathrm{GPa})$ & $\sigma_{\max }(\mathrm{MPa})$ & $\varepsilon(\%)$ & $M_{\mathrm{w}}(\mathrm{kDa})$ \\
\hline PLLA & 0 & $4.4 \pm 0.2$ & $62 \pm 5$ & $1.7 \pm 0.1$ & $77 \pm 3$ \\
Composite 1 & $65 \pm 2$ & $12.4 \pm 1.5$ & $121 \pm 8$ & $3.4 \pm 0.3$ & $86 \pm 4$ \\
Composite 2 & $70 \pm 3$ & $13.4 \pm 0.8$ & $121 \pm 5$ & $2.3 \pm 0.2$ & $71 \pm 3$ \\
Composite 3 & $66 \pm 2$ & $12.7 \pm 0.9$ & $105 \pm 3$ & $2.5 \pm 0.1$ & $78 \pm 3$ \\
Composite 4 & $72 \pm 3$ & $13.6 \pm 0.2$ & $95 \pm 11$ & $1.6 \pm 0.3$ & $59 \pm 3$ \\
BC nanopaper & 1 & $14.9 \pm 1.4$ & $142 \pm 13$ & $2.9 \pm 0.7$ & \\
\hline
\end{tabular}


Table 3: A comparison between the selected tensile properties of (single sheet) BC nanopaper- or BC pellicle-reinforced polymer composites obtained by various authors and the tensile properties of multi-layer BC nanopaper-reinforced PLLA composites produced in this work. $E$ and $\sigma_{\max }$ denote the measured tensile modulus and strength of the composites, respectively.

\begin{tabular}{|c|c|c|c|c|c|}
\hline Polymer & $w_{\mathrm{f}, \mathrm{BC}}(\%)$ & $v_{\mathrm{f}, \mathrm{BC}}(\%)$ & $E(\mathrm{GPa})$ & $\sigma_{\max }(\mathrm{MPa})$ & Ref \\
\hline \multirow[t]{2}{*}{ Cellulose acetate butyrate } & & 10 & 3.2 & 62.6 & {$[15]$} \\
\hline & & 32 & 5.8 & 128.9 & \\
\hline $\begin{array}{l}\text { Polydiethylene glycol bis(allyl } \\
\text { carbonate) }\end{array}$ & & 63 & $6.4 \pm 0.4$ & $130 \pm 9$ & {$[35]$} \\
\hline Epoxy resin & 65 & & 21 & 325 & {$[16]$} \\
\hline Polyurethane & & 79 & 6.0 & 70 & {$[36]$} \\
\hline \multirow[t]{3}{*}{ Polyurethane } & & 31 & $5.4 \pm 0.4$ & 72 & {$[18]$} \\
\hline & & 36 & $9.5 \pm 1.0$ & 124 & \\
\hline & & 51 & $11.6 \pm 1.2$ & 151 & \\
\hline PLLA & & 18 & $4.0 \pm 0.4$ & $115 \pm 10$ & [33] \\
\hline PLLA & & $65 \pm 2$ & $6.9 \pm 0.5$ & $125 \pm 12$ & [17] \\
\hline Epoxidised soybean oil & 75 & & $5.9 \pm 0.5$ & $81 \pm 0.7$ & {$[37]$} \\
\hline PLLA (1 sheet of BC nanopaper) & & $65 \pm 2$ & $12.4 \pm 1.5$ & $121 \pm 8$ & This \\
\hline PLLA (3 sheets of BC nanopapers) & & $70 \pm 3$ & $13.4 \pm 0.8$ & $121 \pm 5$ & work \\
\hline PLLA (6 sheets of BC nanopapers) & & $66 \pm 2$ & $12.7 \pm 0.9$ & $105 \pm 3$ & \\
\hline PLLA (12 sheets of BC nanopapers) & & $72 \pm 3$ & $13.6 \pm 0.2$ & $95 \pm 11$ & \\
\hline
\end{tabular}

Source: Adapted from Lee and Bismarck [38], further developed with the data obtained in this work. 